\title{
Neurocognitive Symptoms and Impairment in an HIV Community Clinic
}

\author{
D.H. Kim, D.L. Jewison, G.R. Milner, S.B. Rourke, M.J. Gill, C. Power
}

\begin{abstract}
Background: Neurocognitive impairment is a frequent complication of HIV infection and heralds a poor survival prognosis. With the availability of highly active antiretroviral therapy (HAART), survival times for HIV-infected patients have markedly increased although the effects of HAART on the prevalence of neurocognitive impairment remain uncertain. Objective: To determine the relationship between self-reported neurocognitive symptoms and neuropsychological (NP) performance together with the impact of HAART among HIV-infected patients. Methods: A cross-sectional study was performed in which patients without previously documented neurocognitive impairment attending an HIV community clinic were questioned about neurocognitive symptoms and a NP test battery was administered. Results: Of the eighty-three patients examined, neurocognitive symptoms were reported by $34 \%$ of patients and were associated with a shorter duration of HAART and higher viral loads. Patients reporting neurocognitive symptoms were also more likely to exhibit impaired NP performance $(\mathrm{p}<0.005)$ with NP impairment being detected in $46 \%$ of all patients examined (12\% with HIVassociated dementia). Neuropsychological impairment was directly correlated with age $(\mathrm{p}<0.001)$, plasma viral load $(\mathrm{p}<0.005)$ and inversely correlated with the number of prescribed antiretroviral drugs $(\mathrm{p}<0.01)$. Conclusions: These results suggest that neurocognitive symptoms are predictive of impaired NP performance and that NP impairment remains a frequent finding among older patients with higher viral loads. An increased number of antiretroviral drugs may be neuroprotective.
\end{abstract}

RÉSUMÉ: Symptômes neurocognitifs et invalidité chez les patients d'une clinique communautaire anti-VIH. Introduction: Le déficit neurocognitif est une complication fréquente de l'infection par le VIH et comporte un mauvais pronostic quant à la survie. Avec l'arrivée de la thérapie antirétrovirale hautement efficace (HAART), la survie des patients infectés par le VIH a augmenté de façon appréciable, bien que l'influence de HAART sur la prévalence du déficit neurocognitif demeure inconnue. Objectif: Déterminer la relation entre les symptômes neurocognitifs rapportés par les patients et la performance neuropsychologique (NP) ainsi que l'impact de HAART chez les patients infectés par le VIH. Méthodes: Dans cette étude transversale, on a questionné des patients d'une clinique communautaire anti-VIH sans déficit neurocognitif documenté sur leurs symptômes neurocognitifs et on leur a administré une batterie de tests NP. Résultats: Parmi les quatre-vingt-trois patients examinés, des symptômes neurocognitifs ont été rapportés par $34 \%$ et ils étaient associés à une administration plus brève de HAART et à une charge viral plus élevée. Les patients qui rapportaient des symptômes neurocognitifs étaient également plus susceptibles d'avoir une performance NPaltérée ( $\mathrm{p}<0.005)$; une altération NPa été détectée chez $46 \%$ de tous les patients examinés (démence associée au VIH chez 12\%). Le déficit NPétait directement corrélé à l'âge ( $\mathrm{p}<0.001$ ), la charge virale plasmatique ( $\mathrm{p}$ 0.005) et inversement corrélé au nombre de médicaments antirétroviraux prescrits ( $p$ < 0.01). Conclusions: Ces résultats suggèrent que les symptômes neurocognitifs sont indicateurs d'une performance NP altérée et que l'altération NP demeure une constatation fréquente chez les patients plus âgés qui ont une charge virale plus élevée. Un nombre croissant de médicaments antirétroviraux puissent être neuroprotecteurs.

Can. J. Neurol. Sci. 2001; 28: 228-231

Human immunodeficiency virus-type 1 (HIV-1) infection causes a spectrum of neurocognitive syndromes ranging from minor cognitive impairment, detectable on neuropsychological (NP) testing, to frank dementia. ${ }^{1}$ Most reports assessing NP performance in HIV-infected patients have been conducted as multicentre studies and are usually composed of self-selected
From the Departments of Clinical Neurosciences (DHK,CP), Microbiology and Infectious Diseases (MJG, CP), University of Calgary, Calgary AB; Southern Alberta Clinic (DLJ, GRM. MJG, CP), Calgary AB; Department of Psychiatry (SBR), University of Toronto, Toronto ON, Canada. ReCeived February 2, 2001. ACCePted infinalform May 29, 2001. Reprint requests to: Christopher Power, Department of Clinical Neurosciences, 3330 Hospital Drive NW, Calgary, Alberta, Canada, T2N 4N1 
volunteers who are motivated to remain in a longitudinal study. ${ }^{2,3}$ These circumstances may not reflect the circumstances for many HIV community clinics and neurology referrals from such clinics. To date, there has been limited evaluation of NP impairment following use of highly active antiretroviral therapy (HAART) with variable results. ${ }^{4-7}$ Furthermore, few studies have addressed the relationship between neurocognitive symptoms and impairment in the setting of an HIV community clinic among patients receiving HAART. The purpose of this crosssectional study was to examine the relationship between neurocognitive symptoms and NP impairment among patients receiving HAART in a community clinic.

\section{Methods}

The Southern Alberta Clinic (SAC) is a community HIV clinic that serves all HIV seropositive patients $(n=780)$ in southern Alberta. All patients attending SAC receive free antiretrovirals and are followed regularly with viral loads and CD4 counts. During routine visits to SAC, patients and/or primary care givers were randomly selected and subsequently questioned, by a registered nurse or a social worker, about symptomatology indicative of (1) memory and concentration dysfunction, (2) difficulty with gait and coordination, (3) change in behavior or social interactions and (4) related difficulties with activities of daily living including self-care (cooking, dressing, management of financial issues) or employment. Patients were designated as symptomatic or asymptomatic depending on the self-reported presence or absence, respectively, of at least two of the above neurological symptomatologies. Patients were excluded from the analysis if they exhibited CNS opportunistic infections, depression confirmed by the clinic psychiatrists (DSM-IVR definitions), debilitating neuropathy, or had a previous diagnosis of cognitive impairment, including previously diagnosed HIV-associated dementia (HAD). After questioning about neurocognitive symptoms, patients underwent routine NP testing including Grooved Pegboard (dominant and non-dominant hands), Trail Making Test: Parts A and B, and Symbol Digit Modalities Test, administered in a standardized manner. These tests were selected because of their proven utility in previous studies of HIV-related NP performance. ${ }^{8,9}$ Results of these NP tests were assessed in relation to previously reported normative data according to age and education. ${ }^{8}$ The mean deficit score (MDS) was calculated, as previously reported, ${ }^{9}$ using the Symbol-Digit Modalities, Trail Making: Part B and Grooved Pegboard (non-dominant hand) Tests. To ensure reliability of the categorization of NP impairment, two definitions were used including (1) a MDS value of greater than 0.50 or (2) a single test score two standard deviations or any two scores one standard deviation below the demographically corrected normative mean for those tests. Relevant demographic and clinical data from the medical records were recorded. The diagnosis of HAD was predicated on testing with the HIV Dementia Scale ${ }^{10}$ and established criteria, ${ }^{11}$ following administration of the NP test battery. Univariate comparisons were made using the Fisher exact test for categorical variables, the Mann-Whitney or Welch-corrected unpaired t tests for continuous variables, and derivation of correlation co-efficients by multiple and single regression analyses (Instat2, Graphpad,
Table: Demographic and clinical features of patients who were neurocognitively asymptomatic and symptomatic

\begin{tabular}{|c|c|c|c|}
\hline Characteristic & $\begin{array}{l}\text { Asymptomatic } \\
\qquad(\mathrm{N}=55)\end{array}$ & $\begin{array}{l}\text { Symptomatic } \\
\quad(\mathbf{N}=28)\end{array}$ & $p$ Value \\
\hline \multicolumn{4}{|l|}{ Demographic } \\
\hline Median Age (yr)(Range) & $42(27-66)$ & $45.5(24-55)$ & NS \\
\hline Gender, No. (\%) Male & $51(92.7)$ & $26(92.8)$ & NS \\
\hline No. (\%) Homo/Bisexual & $38(69.1)$ & $17(60.7)$ & NS \\
\hline No. (\%) IVDrug Users & $4(7.3)$ & $5(17.9)$ & NS \\
\hline Median (Range) Education (yr) & $16(8-21)$ & $13(10-21)$ & NS \\
\hline \multicolumn{4}{|l|}{ Clinical } \\
\hline $\begin{array}{l}\text { Median (Range) Time of } \\
\text { HIVseropositivity (mo) }\end{array}$ & $89(15-168)$ & $71.5(6-189)$ & NS \\
\hline $\begin{array}{l}\text { Median (Range) } \log _{10} \text { Viral } \\
\text { Load (copies } / \mathrm{ml} \text { ) }\end{array}$ & $1.59(1.59-6.86)$ & $3.24(1.59-6.28)$ & $0.0346 *$ \\
\hline $\begin{array}{l}\text { Median (Range) Nadir CD4 } \\
\quad(\text { Count } / \mu \mathrm{l})\end{array}$ & $76(1-582)$ & $81(2-537)$ & NS \\
\hline $\begin{array}{l}\text { Median (Range) Present CD4 } \\
(\text { Count } / \mu \mathrm{l})\end{array}$ & $285(1-1332)$ & $244.5(4-924)$ & NS \\
\hline No. $(\%)$ on HAART ${ }^{\mathrm{a}}$ & $49(89)$ & $20(71)$ & NS \\
\hline $\begin{array}{l}\text { Median (Range) Time on } \\
\text { HAART (mo) }\end{array}$ & $20(0-69)$ & $3.5(0-118)$ & $0.0073 *$ \\
\hline No. (\%) HIV Dementia & $1(1.8)$ & $9(32.1)$ & $0.0002 *$ \\
\hline
\end{tabular}

a highly active antiretroviral treatment (minimum of three antiretrovirals)

* statistically significant difference, NS-nonsignificant

San Diego CA). P values less than 0.05 were considered statistically significant.

\section{Results}

Ninety-five patients were screened regarding the presence of neurocognitive signs and symptoms, of which 83 were included in the present analysis, while the remaining met the predefined exclusion criteria. Fifty-five patients $(66 \%)$ were classified as asymptomatic and $28(34 \%)$ as symptomatic, based on the presence of at least two or more self-reported symptoms. Comparison of demographic and clinical characteristics (Table) revealed that the symptomatic group had a shorter median duration of antiretroviral drug treatment $(\mathrm{p}<0.005)$ with higher viral loads $(\mathrm{p}<0.05)$ and a greater number of individuals diagnosed with HAD $(p<0.0001)$. The prevalence of HAD was $12 \%(10 / 83)$ with a median HIV Dementia Scale score of 8 (range: 4-12) based on the criteria outlined in the Methods section. The asymptomatic and neurocognitively symptomatic groups did not differ significantly in the frequencies of head injury, presence of cytomegalovirus, hepatitis C or B viral infections, antidepressant use, median time since AIDS diagnosis, median nadir CD4 counts and the median number of antiretroviral drugs taken at the time of testing.

Analysis of NP findings revealed that symptomatic patients performed significantly worse on all tests although these differences were least apparent for the Grooved Pegboard tests 

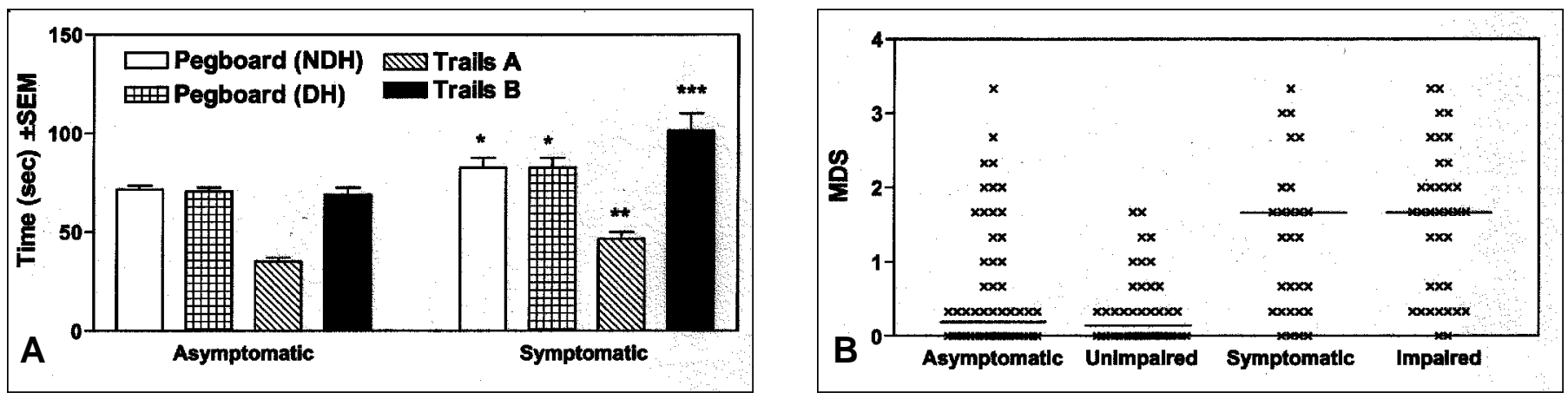

Figure 1: Neuropsychlogical test findings among asymptomatic $(n=55)$, symptomatic $(n=28)$, unimpaired $(n=47)$ and impaired $(n=36)$ HIV-infected patients. (A) Grooved Pegboard and Trail Making Tests (Welch corrected unpaired t test) and (B) Mean Deficit Score (MDS) (Mann Whitney U test, $p<0.005)$ showed significant differences between asymptomatic and symptomatic (A, B) or impaired and unimpaired patients (B). Mean Symbol-Digit Modalities Test scores also differed between symptomatic and asymptomatic patients $(p<0.001)$. Horizontal line indicates median MDS value for each group $(* p<0.05, * * p<0.01, * * * p<0.001)$

(Figure 1A). Similar prevalences of impairment among all patients were found using either definition of neurocognitive impairment: $46 \%(38 / 83)$ with the mean deficit score (MDS) criteria and $43 \%$ (36/83) using the standard deviations definition. Using the MDS criterion for NPimpairment, a greater number of symptomatic patients were found to be NP impaired: $67 \%$ $(19 / 28)$ versus $35 \%(19 / 55)$ in the asymptomatic group $(\mathrm{p}<0.005)$. All test scores with the exception of the dominant hand Grooved Pegboard $(\mathrm{p}<0.05)$ (Figure 1A) were markedly different between the impaired and unimpaired groups $(\mathrm{p}<0.0001)$. The mean MDS $( \pm$ SEM $)$ for the HAD patients was $2.19( \pm 0.35)$. To compare the severity of neurocognitive impairment among asymptomatic versus symptomatic or NP impaired versus NP unimpaired, the MDS for each patient was calculated for both classifications (Figure 1B), revealing similar differences for each classification $(p<0.0001)$. Since MDS provided a continuous variable for each patient with which other variables could be compared, MDS was used in the subsequent analyses.

Median age was the only variable found to differ between the NP impaired, 46 years (range: 34-66) and the unimpaired patients, 38 years (range: $24-58)(\mathrm{p}<0.0005)$. While the median number of patients on HAART did not differ between the NP impaired and unimpaired groups $(\mathrm{p}>0.05)$, age $(\mathrm{p}<0.001)$ and viral load $(\mathrm{p}<0.005)$ in plasma were found to be correlated positively with MDS. In addition, the number of antiretroviral drugs patients were taking was inversely correlated with MDS (Spearman $\mathrm{r}=-0.2725 ; \mathrm{p}<0.01$ ). The remaining continuous variables (education, duration of HAART, and nadir CD4 levels) were not significantly correlated with the MDS.

\section{DISCUSSION}

Neurocognitive symptoms are often difficult to interpret clinically in the face of significant systemic disease that occurs in illnesses such as HIV/AIDS. However, the present study illustrates several relevant points that address this issue among patients who were followed routinely in an HIV community clinic. Patients who report neurocognitive symptomatology performed significantly worse on NP testing and furthermore, a greater percentage of patients with neurocognitive symptoma- tology were cognitively impaired, compared to asymptomatic patients. Despite the exclusion of patients with CNS opportunistic infections, debilitating neuropathy, a previous history of cognitive impairment together with the universal availability of HAART within this clinic, NP impairment was detected in $46 \%$ of tested patients and was correlated with viral load and age. Finally, the number of antiretrovirals taken by patients was inversely related to the severity of NP impairment with a predominant effect on improved psychomotor efficiency, which is in agreement with earlier studies. ${ }^{6,12}$

Although median plasma viral loads did not differ significantly between the NP impaired and unimpaired groups, there was a trend towards an increased viral load among the NP impaired group. Moreover, the present findings indicate that viral load was correlated with MDS among all eighty-three patients. This latter observation is at odds with earlier studies, performed prior to the availability of HAART in which plasma viral load was not correlated with neurocognitive impairment. ${ }^{13,14}$ More recent studies suggest that plasma viral loads may be higher in patients with NPimpairment who receive HAART ${ }^{5,7}$ Since the number of antiretrovirals taken was also correlated with NP performance, the implication of these findings is that HAART-associated reductions in viral load might have a beneficial effect on NP performance. Indeed, this may reflect combined therapeutic effects on viral replication in the brain and plasma and perhaps, neurocognitive symptoms and impairment may be useful surrogate indicators of rising viral load and/or drug resistance. Within the Southern Alberta Clinic, there is preference towards using CNS penetrating drugs including stavudine, zidovudine, abacavir and lamivudine to minimize lipodystrophy occurrence. The effects of the predominant use of these drugs on CNS function remains uncertain.

Group ages differed between the NPimpaired and unimpaired groups with the impaired patients tending to be older and similarly, MDS was also significantly correlated with age. Earlier studies show conflicting results on the effect of age on HIV-related NP impairment ${ }^{1,15,16}$ with one study showing no effect and the other showing a positive correlation. However, several concerns in the current study should be considered. The cross-sectional design and relatively small sample size may 
predispose to biased results. Although a limited, highly-selected NP battery is practical on day-to-day basis as shown in the present study, a small NP test battery (less than nine tests) has been shown to miss subtle deficits. ${ }^{17}$ Nonetheless, the present study battery was sufficient to identify patients that had previously unrecognized HAD. Finally, since this study was performed in a Canadian HIV community clinic, the impact of universal health care may result in findings that differ from those in the United States where optimized HAART regimens may not be as available to all patients.

We conclude that in the setting of an HIV community clinic, it is useful to assess HIV/AIDS patients who report neurocognitive symptoms because these symptoms are frequently associated with impaired NPperformance, which may respond to an increased number of antiretroviral drugs. Future prospective studies examining the relationship between HAART use and the development of neurocognitive symptoms and NP impairment may identify optimal HAART regimens that are neuroprotective and elucidate some of the neuropathogenic mechanisms underlying HIV-induced NP impairment.

\section{ACKNOWLEDGEMENTS}

The authors thank Bill Richardson and Brenda Beckthold for assistance with data analysis and Belinda Ibrahim for manuscript preparation.

\section{REFERENCES}

1. Janssen RS, Nwanyanwu OC, Selik RM, et al. Epidemiology of human immunodeficiency virus encephalopathy in the United States. Neurology 1992; 42: 1472-1476.

2. Heaton RK, Grant I, Butters N, et al. The HNRC 500 neuropsychology of HIV infection at different disease stages. HIV Neurobehavioral Research Center. J Int Neuropsychol Soc 1995; $1: 231-251$.

3. Miller EN, Selnes OA, McArthur JC, et al. Neuropsychological performance in HIV-1-infected homosexual men: the Multicenter AIDS Cohort Study (MACS) [see comments]. Neurology 1990; 40: $197-203$.

4. Dore GJ, Correll PK, Li Y, et al. Changes to AIDS dementia complex in the era of highly active antiretroviral therapy. AIDS 1999; 13: 1249-1253.
5. Ferrando S, van Gorp W, McElhiney $M$, et al. Highly active antiretroviral treatment in HIV infection: benefits for neuropsychological function. AIDS 1998; 12: F65-70.

6. Tozzi V, Balestra P, Galgani S, et al. Positive and sustained effects of highly active antiretroviral therapy on HIV-1-associated neurocognitive impairment [In Process Citation]. AIDS 1999; 13: 1889-1897.

7. Price RW, Y iannoutos T, Clifford DB, et al. Neurological outcomes in late HIVinfection: adverse impact of neurological survival and protection effect of antiretroviral therapy. AIDS 1999; 13: 16771685.

8. Selnes OA, Jacobson L, Machado AM, et al. Normative data for a brief neuropsychological screening battery. Multicenter AIDS Cohort Study. Percept Mot Skills 1991; 73: 539-550.

9. Heseltine PN, Goodkin K, Atkinson JH, et al. Randomized doubleblind placebo-controlled trial of peptide T for HIV- associated cognitive impairment. Arch Neurol 1998; 55: 41-51.

10. Power C, Selnes OA, Grim JA, et al. HIV Dementia Scale: a rapid screening test. J Acquir Immune Defic Syndr Hum Retrovirol 1995; 8: 273-278.

11. Janssen R. Nomenclature and research case definitions for neurologic manifestations of human immunodeficiency virustype 1 (HIV-1) infection. Report of a Working Group of the American Academy of Neurology AIDS Task Force [see comments]. Neurology 1991; 41: 778-785.

12. Sacktor NC, Skolasky RL, Lyles RH, et al. Highly active antiretroviral therapy (HAART) improves cognitive impairment in HIV+ homesexual men. Neuroscience of HIV infection. J Neurovirol 1998; 4 (suppl): 365.

13. McArthur JC, McClernon DR, Cronin MF, et al. Relationship between human immunodeficiency virus-associated dementia and viral load in cerebrospinal fluid and brain [see comments]. Ann Neurol 1997; 42: 689-698.

14. Ellis RJ, Deutsch R, Heaton RK, et al. Neurocognitive impairment is an independent risk factor for death in HIV infection. San Diego HIV Neurobehavioral Research Center Group. Arch Neurol 1997; 54: 416-424.

15. McArthur JC, Hoover DR, Bacellar H, et al. Dementia in AIDS patients: incidence and risk factors. Multicenter AIDS Cohort Study. Neurology 1993; 43: 2245-2252.

16. van Gorp WG, Miller EN, Marcotte TD, et al. The relationship between age and cognitive impairment in HIV-1 infection: findings from the Multicenter AIDS Cohort Study and a clinical cohort. Neurology 1994; 44: 929-935.

17. White DA, Heaton RK and Monsch AU. Neuropsychological studies of asymptomatic human immunodeficiency virus- type-1 infected individuals. The HNRC Group. HIV Neurobehavioral Research Center. J Int Neuropsychol Soc 1995; 1: 304-315. 